\title{
Differential regulation of the a-globin locus by Krüppel-like factor 3 in erythroid and non-erythroid cells
}

\author{
Alister PW Funnell1', Douglas Vernimmen², Wooi F Lim', Ka Sin Mak , Beeke Wienert ${ }^{1}$, Gabriella E Martyn ${ }^{1}$, \\ Crisbel M Artuz ${ }^{1}$, Jon Burdach', Kate GR Quinlan', Douglas R Higgs ${ }^{3}$, Emma Whitelaw ${ }^{4}$, Richard CM Pearson ${ }^{1}$ \\ and Merlin Crossley ${ }^{1 *}$
}

\begin{abstract}
Background: Krüppel-like Factor 3 (KLF3) is a broadly expressed zinc-finger transcriptional repressor with diverse biological roles. During erythropoiesis, KLF3 acts as a feedback repressor of a set of genes that are activated by Krüppel-like Factor 1 (KLF1). Noting that KLF1 binds a-globin gene regulatory sequences during erythroid maturation, we sought to determine whether KLF3 also interacts with the $a$-globin locus to regulate transcription.

Results: We found that expression of a human transgenic a-globin reporter gene is markedly up-regulated in fetal and adult erythroid cells of $\mathrm{KIf}^{-/-}$mice. Inspection of the mouse and human a-globin promoters revealed a number of canonical KLF-binding sites, and indeed, KLF3 was shown to bind to these regions both in vitro and in vivo. Despite these observations, we did not detect an increase in endogenous murine a-globin expression in $\mathrm{Klf}^{-/-}$erythroid tissue. However, examination of murine embryonic fibroblasts lacking KLF3 revealed significant de-repression of a-globin gene expression. This suggests that KLF3 may contribute to the silencing of the a-globin locus in non-erythroid tissue. Moreover, ChIP-Seq analysis of murine fibroblasts demonstrated that across the locus, KLF3 does not occupy the promoter regions of the a-globin genes in these cells, but rather, binds to upstream, DNase hypersensitive regulatory regions.

Conclusions: These findings reveal that the occupancy profile of KLF3 at the a-globin locus differs in erythroid and non-erythroid cells. In erythroid cells, KLF3 primarily binds to the promoters of the adult a-globin genes, but appears dispensable for normal transcriptional regulation. In non-erythroid cells, KLF3 distinctly binds to the HS-12 and HS-26 elements and plays a non-redundant, albeit modest, role in the silencing of a-globin expression.
\end{abstract}

Keywords: KLF1, KLF3, Alpha globin, Globin gene regulation, Transcription factor

\section{Background}

Krüppel-like Factor 3 (KLF3/BKLF) belongs to the KLF family of transcription factors, of which there are 17 members with diverse biological roles in development and cellular differentiation [1,2]. KLFs are characterized by a highly homologous C-terminal DNA-binding domain, containing three $\mathrm{C} 2 \mathrm{H} 2$ zinc fingers that direct binding to CACCC boxes and related GC-rich sequences in the control regions of target genes [3]. KLF3 is predominantly a transcriptional repressor which recruits a co-repressor

\footnotetext{
*Correspondence: m.crossley@unsw.edu.au

${ }^{1}$ School of Biotechnology and Biomolecular Sciences, University of New South Wales, Sydney, NSW 2052, Australia

Full list of author information is available at the end of the article
}

complex containing $\mathrm{C}$-terminal binding protein (CtBP) to facilitate silencing of its target genes [4]. KLF3 is broadly expressed and has been shown to have roles in several processes, including erythropoiesis [5,6], adipogenesis $[7,8]$, muscle cell differentiation [9], and B cell development $[10,11]$.

The Klf3 gene is highly expressed in the red blood cell lineage due to the presence of an erythroid specific promoter, which is driven by a related KLF, Krüppel-like Factor 1 (KLF1) [12]. KLF1 is a master regulator of erythropoiesis, with functional roles in many facets of erythroid development, including red blood cell structure, heme biosynthesis and globin gene regulation [13,14]. Loss of KLF1 is embryonic lethal, with $\mathrm{Klf1}^{-/-}$mice dying in utero from 
lethal $\beta$-thalassemia, due to a failure of activation of $\beta$-globin gene expression $[15,16]$. In addition to regulating the $\beta$-globin gene, KLF1 has been shown to bind the $\alpha$-globin locus [17-19], as a component of a complex of factors recruited when looping of enhancer elements to the proximal promoter occurs and initiates high level gene expression $[17,20]$. Loss of KLF1 leads to reduced $\alpha$-globin gene expression and chromosome looping [21], although these effects are notably less severe than the downregulation of $\beta$-globin expression, possibly due to functional redundancy between other KLF family members and related SP (specificity protein) factors [17]. In regulating both the $\alpha$-globin and $\beta$-globin loci, it is probable that KLF1 contributes to the maintenance of globin chain balance, which is critical for red blood cell function and viability.

Given that KLF3 is required for normal erythropoiesis and is known to repress a subset of KLF1-driven target genes [5], we investigated whether KLF3 can also bind and repress the $\alpha$-globin gene. In support of this, we found that expression of a GFP reporter transgene, driven by the human $\alpha$-globin promoter and regulatory elements [22] is significantly up-regulated in $\mathrm{Klf3}^{-/-}$mice. Furthermore, inspection of the $\alpha$-globin promoter revealed numerous KLF3 consensus recognition sites and we confirmed that KLF3 binds to this region both in vitro in electrophoretic mobility shift assays and in vivo by chromatin immunoprecipitation. However, despite demonstrating an in vivo interaction of KLF3 with the $\alpha$-globin locus, we did not detect de-regulated endogenous $\alpha$-globin expression in $\mathrm{Klf3}^{-/-}$erythroid tissue. In contrast, examination of $\alpha$-globin mRNA levels in $\mathrm{Klf3}^{-/-}$murine embryonic fibroblasts revealed a significant increase in expression. In fibroblasts, KLF3 was found to bind not at $\alpha$-globin promoter regions, but at the upstream $H S-12$ and $H S$ - 26 regulatory regions. Together, these results suggest that KLF3 may have a role in the silencing of the $\alpha$-globin locus in non-erythroid tissue.

\section{Methods}

\section{Mouse lines}

The generation of GFP Line3 [22] and $\mathrm{Klf3}^{-/-}$[8] lines have been described previously. Mice were maintained on the FVBN/J background and animal work was carried out under the approval of the Animal Care and Ethics Committees of the University of Sydney (project numbers L02/1-2005/3/4048, L02/6-2006/3/4344 and L02/7-2009/ $3 / 5079$ ) and the University of New South Wales (approval number 09/128A).

\section{Cell sorting and flow cytometry}

Flow cytometry was performed using a FACSCalibur Flow Cytometer (BD Biosciences, San Jose, CA) and data were analyzed using CellQuest Pro (BD Biosciences) or
FlowJo v7.6.5 software (TreeStar, Ashland, OR). TER119 antibody was supplied by BD Biosciences and titrated to optimal concentration. TER $119^{+}$cells were purified from embryonic day 14.5 fetal liver $\left(\mathrm{Klf3}^{+/+}, \mathrm{Klf3}^{+/-}\right.$ and $\mathrm{Klf3}^{-1-}$ littermates) using Magnetic Activated Cell Sorting with Anti-TER119 MicroBeads (Miltenyi Biotec Australia Pty Ltd, Macquarie Park, NSW, Australia) by positive selection using MS columns as per the supplier's instructions.

\section{Cell culture}

Mouse and human primary erythroblasts, murine erythroleukemia (MEL) cells and interspecific MEL hybrids (containing a copy of human chromosome 16) were cultured and differentiated as previously described [17]. K562 cells were cultured at $37^{\circ} \mathrm{C}$ in RPMI medium and COS-7 cells were cultured in Dulbecco's Modified Eagle Medium (DMEM), each supplemented with $10 \%(\mathrm{v} / \mathrm{v})$ fetal calf serum (FCS) and $1 \%(\mathrm{v} / \mathrm{v})$ penicillin, streptomycin and glutamine solution (PSG) (Gibco-BRL Life Technologies, Grand Island NY). Murine embryonic fibroblasts (MEFs) were prepared from littermate E12.5 embryos $\left(\mathrm{Klf3}^{+/+}\right.$, $\mathrm{Klf3}^{+/-}$and $\mathrm{Klf3}^{-/-}$). Briefly, heart, liver, intestinal, lung and brain tissue were removed and remaining embryonic tissue was homogenized in $3 \mathrm{~mL}$ trypsin/EDTA using an 18-gauge needle. MEFs were subsequently incubated for 2-3 minutes at $37^{\circ} \mathrm{C}$ and were then transferred to $100 \mathrm{~mm}$ plates containing $7 \mathrm{~mL}$ DMEM (10\% FCS, $1 \%$ PSG). The cells were then left undisturbed for $48 \mathrm{~h}$ at $37^{\circ} \mathrm{C}$ and were passaged every $2-3$ days. MEF cells (passage 2 or 3 ) were immortalized by transfecting with $5 \mu \mathrm{g}$ pRSV-T [23] using the FuGENE6 transfection reagent protocol (Roche Diagnostics Australia Pty Ltd, Castle Hill, NSW, Australia). Immortalized $\mathrm{Klf3}^{-1-}$ MEFs that have been stably rescued with KLF3-V5, or pMSCVpuro empty vector (Clontech Laboratories, Mountain View, CA) as a negative control, have been described previously [24].

\section{RNA extraction and CDNA synthesis}

RNA extraction was performed using TRI-Reagent, according to the manufacturer's guidelines (Sigma, St. Louis, $\mathrm{MO})$. RNA samples were further purified using RNeasy columns (Qiagen, Victoria, Australia) and by treating with DNase I (Ambion, Austin, TX). Subsequently, cDNA was prepared using Superscript VILO cDNA synthesis kit (Invitrogen, Carlsbad, CA), according to the manufacturer's instructions.

\section{Primers and real-time RT-PCR}

Primer sequences for real-time RT-PCR were: mouse $\alpha$ globin, 5'-GTCACGGCAAGAAGGTCGC-3' and 5'-G GGGTGAAATCGGCAGGGT-3'; mouse $\beta$-actin, $5^{\prime}$-GC TTCTTTGCAGCTCCTTCGT-3' and 5' - CCAGCGCA GCGATATCG-3'; mouse 18S, 5'-CACGGCCGGTACA 
GTGAAAC-3' and 5'-AGAGGAGCGAGCGACCAA-3'; mouse Gapdh, 5'-GTCTCCTGCGACTTCAGC-3' and 5' -TCATTGTCATACCAGGAAATGAGC-3'; and as described previously for Klf3, Klf8 and Fam132a [7,12,25]. Quantitative real-time PCR was performed using Power SYBR Green PCR Master Mix and the 7500 Fast RealTime PCR System (Applied Biosystems, Foster City, CA), as described previously [26]. Data were analyzed using 7500 Software v2.0.4 (Applied Biosystems).

\section{Electrophoretic mobility shift assays (EMSAs)}

EMSAs were carried out as described previously [27]. COS-7 cells in $100 \mathrm{~mm}$ plates were transfected with $5 \mu \mathrm{g}$ vector (pMT3-empty or pMT3-Klf3 [28]) using FuGENE6 (Roche Diagnostics Australia Pty Ltd) as per the manufacturer's protocol. Nuclear extracts from COS-7, uninduced K562, uninduced MEL and MEF cell lines were harvested as previously described [28]. Oligonucleotides used in the synthesis of radiolabelled probes were: human $\alpha$-globin promoter, 5'-CGCAGGCCCCGCCCGGGACTC-3' and 5'-GAGTCCCGGGCGGGGCCTGCG-3'; mouse $\alpha$-globin promoter, 5'-TGGAGGACACGCCCTTGGAGG-3' and 5' -CCTCCAAGGGCGTGTCCTCCA-3'; mouse HS-26 probe 1, 5' -AGGTGTACACACCCAGGCCAA-3' and 5' -TTGGCCTGGGTGTGTACACCT-3', and; HS-26 probe 2, 5' '-AGGCCAAGGGTGGAGCAGACCA-3' and 5' -TGG TCTGCTCCACCCTTGGCCT-3'. Supershift recognition of KLF3 was achieved using specific antiserum that has been described previously [27]. Probe sequences were identified using CLC Main Workbench software version 6.6.2 (CLC Bio, Cambridge, MA).

\section{Chromatin immunoprecipitation (ChIP)}

ChIP assays were carried out as previously described $[17,29]$, using the previously described anti-KLF3 antibody [27]. KLF3 ChIP-Seq analysis has previously been described [24] and enrichment tracks were visualized using Integrative Genomics Viewer [30].

\section{Western blotting}

Western blots of nuclear extracts from MEF, MEL and COS-7 cells were performed as previously described [31] using KLF3 anti-serum [27]. Full-Range Rainbow Molecular Weight Marker was supplied by GE Healthcare (Piscataway, NJ).

\section{Results}

KLF3 regulates expression of a human transgenic a-globin promoter in vivo

To begin our investigation into potential regulation of the $\alpha$-globin gene by KLF3, we made use of an existing wellcharacterized transgenic mouse model, termed Line3, in which a GFP reporter gene is expressed under the control of the human $\alpha$-globin proximal promoter and $H S-40$ enhancer region [22]. The red blood cells of Line3 mice express GFP and it is possible to accurately measure the level of expression by flow cytometry in either adult peripheral blood or erythroid cells purified from tissues, such as the fetal liver. To determine whether KLF3 has a role in regulating expression of the reporter gene, we introduced the homozygous transgene into $\mathrm{Klf3}^{-/-}$mice [8] by breeding and compared GFP expression in $\mathrm{Klf3}^{+/+}, \mathrm{Klf3}^{+/-}$and $\mathrm{Klf3}^{-/-}$erythrocytes.

As previously reported [22], we found that GFP is expressed in Line3::Klf3 $3^{+/+}$erythrocytes with a broad, but consistent and reproducible profile. These cells can be classified as expressing low, intermediate or high levels of GFP (Figure 1). Loss of a single allele of Klf3 had no effect on transgene expression, as we did not find any notable difference between the GFP profiles of Line3:: $\mathrm{Klf3}^{+/+}$and Line3:: $\mathrm{Klf3}^{+/-}$mice (Figure $1 \mathrm{~A}$ and $1 \mathrm{C}$ ). However, analysis of red blood cells from homozygous Line3:: $\mathrm{Klf}^{-/-}$animals revealed a significant increase in GFP expression (Figure 1A). On average, we found that $46 \%$ of $\mathrm{Klf3}^{-/-}$cells express high levels of GFP, compared to $18 \%$ in $\mathrm{Klf3}^{+/+}$animals (Figure $1 \mathrm{C}$ ). We also examined newly formed erythrocytes in the erythroid fetal liver. We purified TER119+ cells from the fetal livers of Line3:: $\mathrm{Klf3}^{+/+}$and Line3::Klf3 ${ }^{-/-}$mice and again observed a significant increase in transgenic promoter activity in the absence of KLF3 (Figure 1B and 1D). Together, these data suggest that KLF3 directly or indirectly represses the human transgenic $\alpha$-globin promoter in this mouse model.

\section{KLF3 binds the human and mouse a-globin promoters in vitro and in vivo}

Having determined that KLF3 influences the expression of a transgene driven by $\alpha$-globin gene regulatory sequences in vivo, we next investigated whether KLF3 interacts directly with the $\alpha$-globin promoter. We inspected the human and mouse $\alpha$-globin proximal promoters to identify potential high affinity KLF3 binding sites, which match the KLF consensus sequence, 5' -NCN CNC CCN-3' [32]. This analysis revealed the presence of several sites, with the human promoter in particular containing 14 potential interaction motifs (Figure 2A and 2B). We then used our sequence analysis to design probes for electrophoretic mobility shift assays (EMSA) to investigate binding of KLF3 to the $\alpha$-globin promoter in vitro. To assess binding to the human promoter, we based our probe on the most frequently seen consensus sequence, 5 '-NCC CGC CCN-3', which occurs four times (Figure 2A). In the case of the mouse promoter, where there are noticeably fewer potential KLF3 binding sites (Figure 2B), we used the sequence $5^{\prime}$-NCA CGC CCN-3', which is found twice, to inform our probe design.

We began our investigation into in vitro binding by expressing KLF3 in COS-7 cells and assessing the ability 


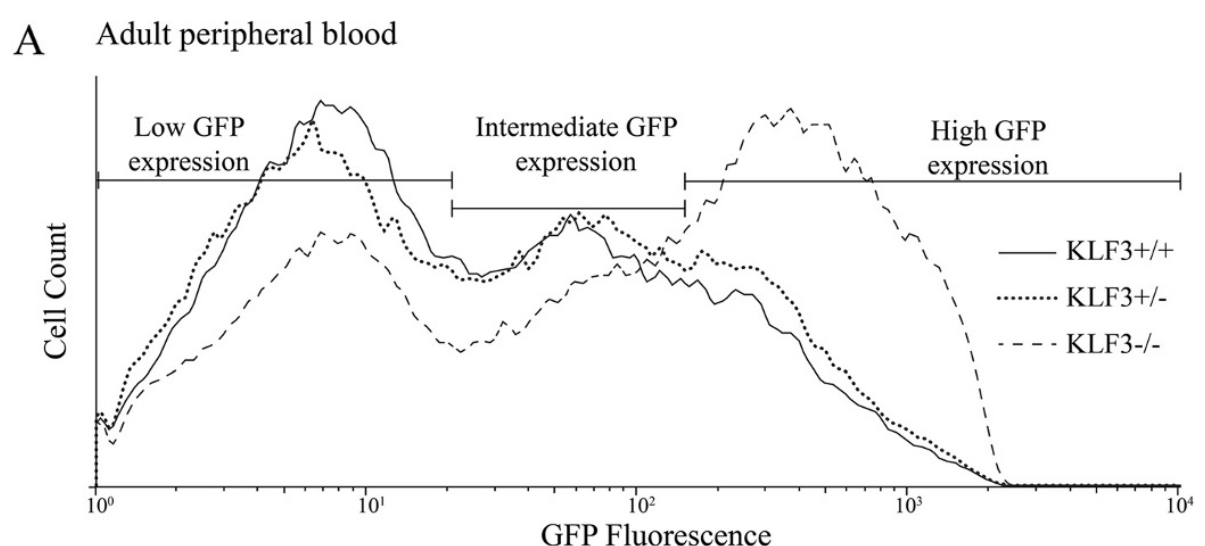

B Fetal Liver

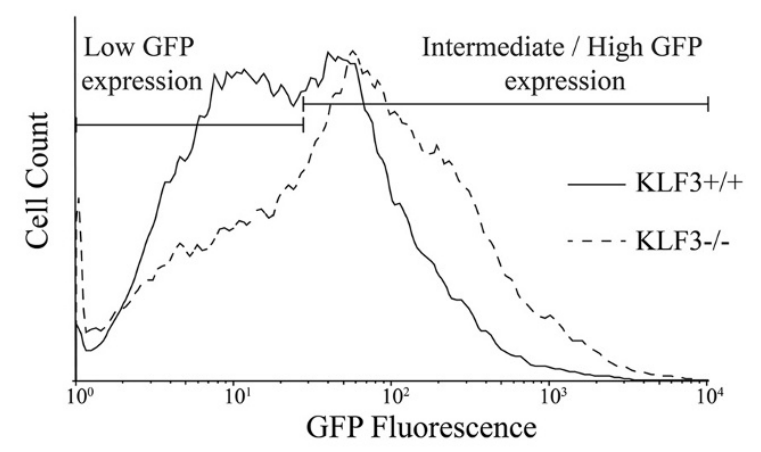

C Adult peripheral blood

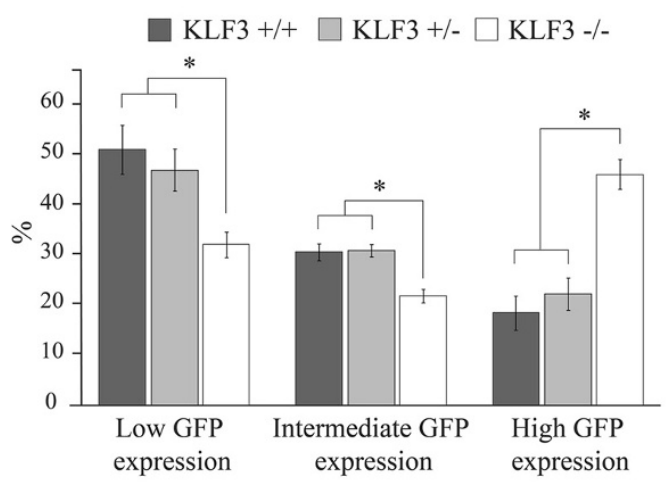

D Fetal Liver

$\mathrm{KLF} 3+/+\square \mathrm{KLF} 3-/-$

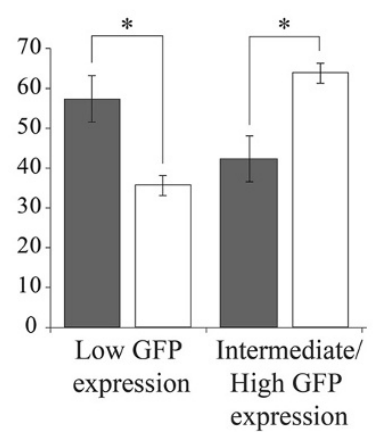

Figure 1 Loss of KLF3 results in up-regulation of the human a-globin gene in a transgenic mouse model. Line3 mice, containing a GFP transgene under the control of the human a-globin proximal promoter and HS-40 enhancer [22], were crossed with $\mathrm{KIF}^{+/-}$mice to generate Line3::KIf3 ${ }^{+/+}$, Line3::KIf3 ${ }^{+-}$and Line3::Klf3 ${ }^{-/-}$mice, all homozygous for the transgene. Erythroid GFP fluorescence was then measured by flow cytometry. Shown are representative fluorescence profiles of (A) peripheral blood from mice at 3 weeks of age and (B) TER $119^{+}$sorted erythrocytes from embryonic day E14.5 fetal liver. The populations were gated to identify cells expressing low, intermediate and high levels of GFP. Statistical analysis of these gated populations is shown for (C) erythrocytes from mice at 3 weeks of age and (D) TER119+ fetal liver cells. For erythrocytes analyzed at 3 weeks of age, $n=32$ for Line3::Klf3 ${ }^{+/+}, n=48$ for Line3::KIf3 ${ }^{+/-}$and $n=8$ for Line3::Klf3 ${ }^{-/-}$. For the analysis of fetal erythrocytes, $\mathrm{n}=3$ for Line3::KIf3 ${ }^{+/+}$and $\mathrm{n}=4$ for Line3::KIf3 ${ }^{-/-}$. Error bars represent standard deviation and * represents $P<0.05$ (two tailed t-test).

of nuclear extracts purified from these cells to interact with the human and mouse $\alpha$-globin promoter sequences by EMSA. We found that the nuclear extracts bound both human and mouse probes with high affinity and confirmed that this interaction was specific to KLF3 by supershift with anti-KLF3 antibody (Figure 3, lanes $2-3$ and 7-8). Minimal background binding was observed for nuclear extracts from mock transfected COS-7 cells (Figure 3, lanes 1 and 6). We next determined whether endogenous KLF3 present in erythroid cell lines also binds to the human and mouse $\alpha$-globin promoter probes by preparing nuclear extracts from 


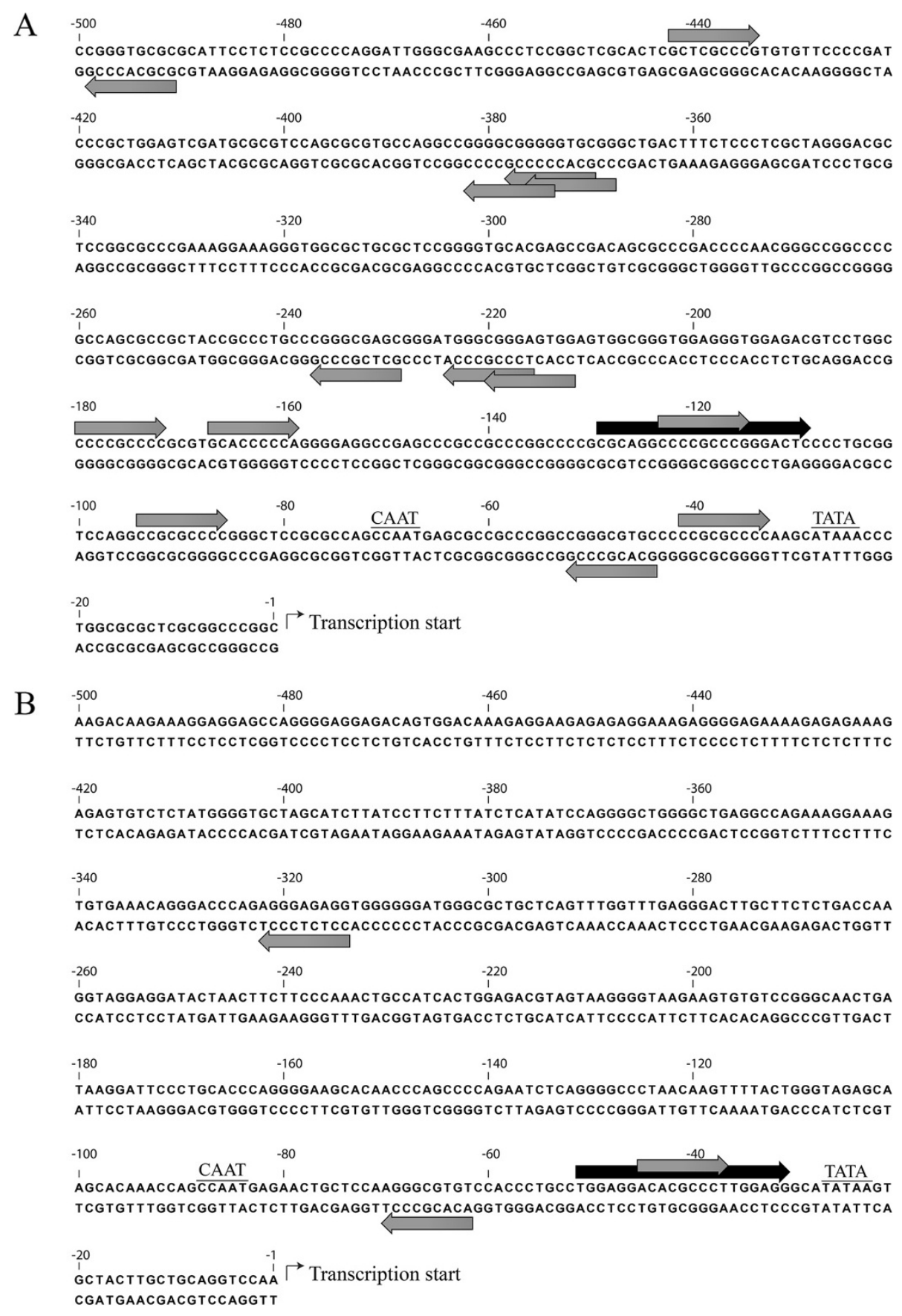

Figure 2 The a-globin promoter contains many consensus KLF3 binding sites. The human HBA2 (A) and mouse Hba-a2 (B) a-globin proximal promoter sequences, immediately $5^{\prime}$ to the transcriptional start site, were inspected for consensus binding sites, conforming to the sequence $5^{\prime}-\mathrm{NCN}$ CNC CCN-3'. The position and direction of binding sites are indicated by grey arrows. The sequences used in the design of probes for electrophoretic mobility shift assays are shown by black arrows. Also indicated are CAAT and TATA boxes. Sequences are numbered with respect to the transcription start site at +1 .

human K562 and murine erythroleukemia (MEL) cells. We tested binding of the K562 nuclear extracts to the human $\alpha$-globin probe and the MEL nuclear extracts to the mouse probe. Again, we found that proteins in both extracts bound to the promoter sequences and confirmed the identity of a KLF3 complex by supershift with an anti-KLF3 antibody (Figure 3, lanes 4-5 and 9-10).

Having established that KLF3 can bind to both the human and mouse $\alpha$-globin proximal promoters in vitro, 


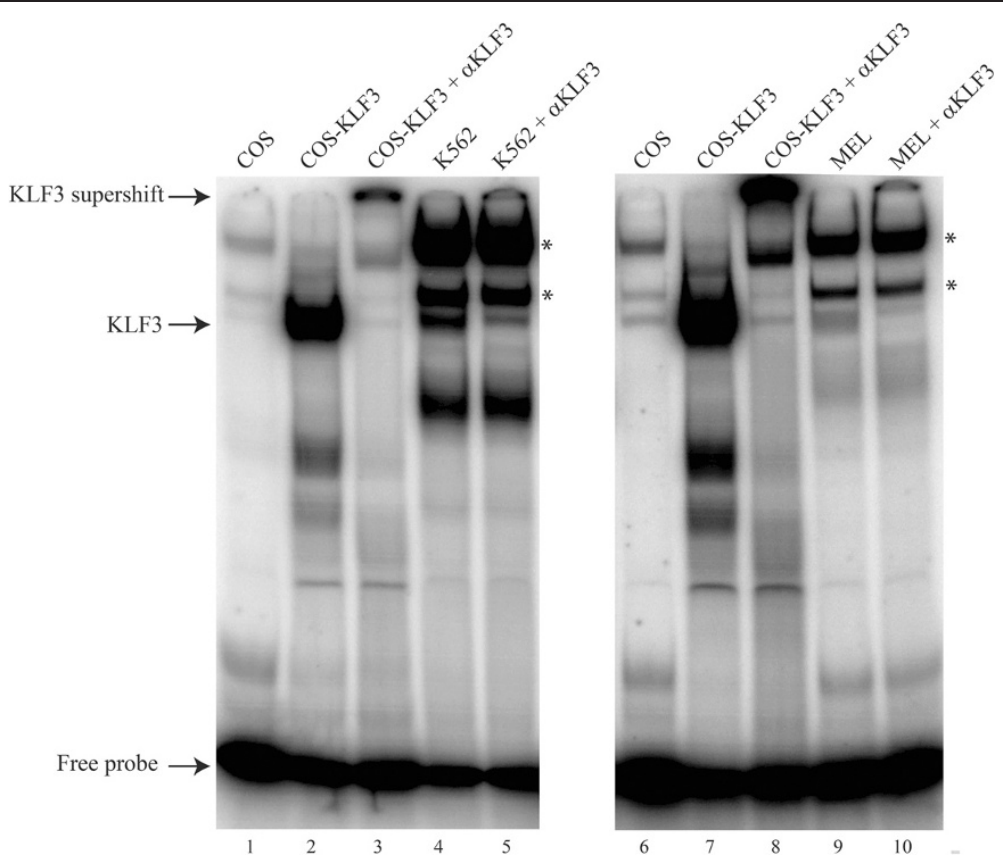

Figure 3 KLF3 binds the a-globin promoter in vitro. The binding of KLF3 to the a-globin promoter was assessed by EMSA, using radiolabeled probes designed from analysis of the human and mouse a-globin proximal promoter sequences (Figure 2). KLF3 was either expressed in COS-7 cells (lanes 2, 3, 7 and 8) or endogenous KLF3 was harvested in nuclear extracts from K562 (lanes 4 and 5) and MEL (lanes 9 and 10) erythroid cell lines. Nuclear extracts from mock transfected COS-7 cells have been included as a negative control (lanes 1 and 6). Binding to the human promoter sequence is shown in the left hand panel whilst binding to the mouse sequence is shown on the right. aKLF3 indicates an anti-KLF3 antibody used to validate KLF3 specific binding by supershift. Additional bands in lanes 4, 5, 9 and 10 (denoted by asterisks) most likely represent SP1 and SP3 as in [12].

we carried out chromatin immunoprecipitation (ChIP) assays on a number of erythroid cell types to determine whether KLF3 binds to the $\alpha$-globin locus in vivo. Our approach was to conduct a primer walk across the locus, in which we used TaqMan real time RT-PCR probes to assess binding at the upstream HS (DNase hypersensitive) enhancers, the proximal promoter, the coding sequence, and at a number of control sites, including the $\alpha$-globin intergenic region, and the $\beta$-actin and $\beta$-globin genes.

First, we investigated KLF3 binding to the $\alpha$-globin locus in uninduced MEL cells and found only background binding at each of the sites we examined (Figure 4A). However, when we chemically induced erythroid maturation in these cells, we observed a marked enrichment of KLF3 at the $\alpha$-globin proximal promoter (Figure 4B), consistent with what we have previously reported [6]. An examination of mouse primary erythroblasts confirmed that KLF3 also binds this site in vivo (Figure 4C). We then made use of an interspecies hybrid MEL cell line into which human chromosome 16, containing the $\alpha$-globin locus, has been introduced $[17,33]$. Again, we saw only background binding of KLF3 across the locus in uninduced cells but observed noticeable enrichment at the human $\alpha$-globin proximal promoter following erythroid maturation (Figure 4D and E). Finally, we assessed binding in human primary erythroblasts and once again found high enrichment at the $\alpha$-globin proximal promoter (Figure 4F).

\section{KLF3 represses a-globin expression in non-erythroid tissue}

Having confirmed that KLF3 can bind to the $\alpha$-globin promoter in vitro and in vivo, we next asked whether loss of KLF3 results in de-regulation of endogenous $\alpha$-globin gene expression. We first compared $\alpha$-globin mRNA levels in red blood cells purified from the erythroid fetal liver of $\mathrm{Klf3}^{+/+}, \mathrm{Klf3}^{+/-}$and $\mathrm{Klf3}^{-/-}$embryos (E14.5) by real time qRT-PCR. Despite our observation that KLF3 binds the $\alpha$-globin gene promoter in vivo, we did not detect any up-regulation of $\alpha$-globin expression in $\mathrm{Klf3}^{-/-}$erythroid cells (Figure 5A). In addition, we have previously analyzed the expression of multiple globin genes at an earlier stage of development (E13.5) and similarly observed no change in adult $\alpha$-globin transcripts in the absence of KLF3 [6].

It is possible that in erythroid cells, loss of KLF3 has little effect because $\alpha$-globin is expressed at maximal levels. We therefore turned our attention to non-erythroid cells, namely murine embryonic fibroblasts (MEFs), which express only low levels of $\alpha$-globin transcripts. In both primary and immortalized MEFs lacking KLF3, we observed a modest de-repression of $\alpha$-globin gene expression (by 
A

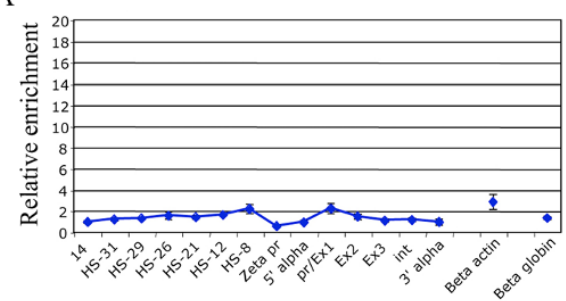

B

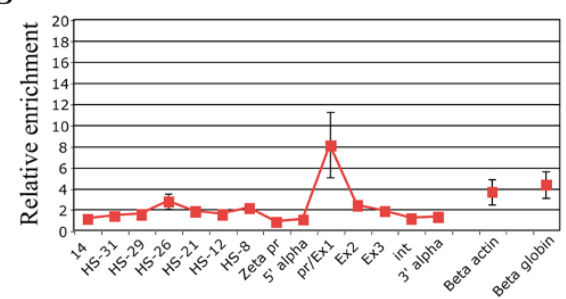

$\mathrm{C}$

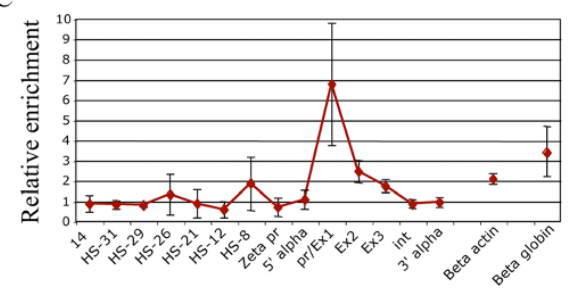

$\mathrm{D}$

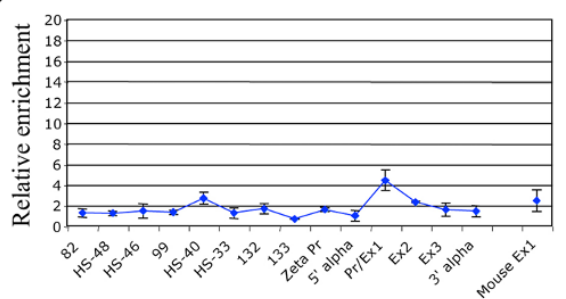

$\mathrm{E}$

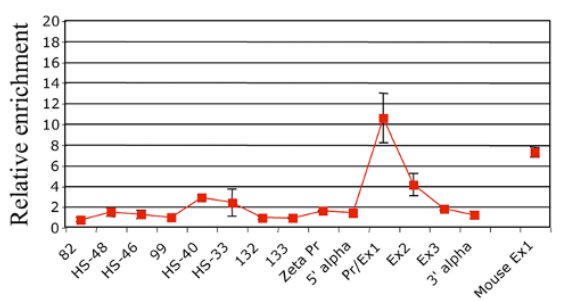

$\mathrm{F}$

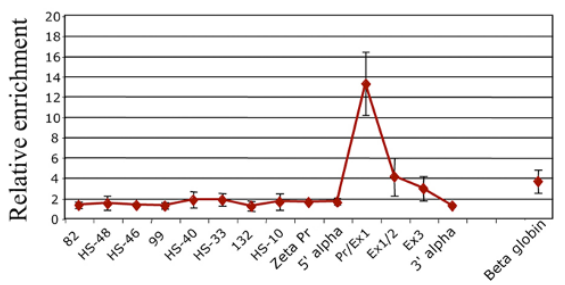

Figure 4 KLF3 binds the human and mouse a-globin promoters in vivo in chromatin immunoprecipitation assays. An anti-KLF3 antibody was used to immunoprecipitate chromatin from the following cell types: (A) uninduced MEL cells, (B) induced MEL cells, (C) mouse primary erythroblasts, (D) uninduced interspecific MEL hybrids containing a normal copy of human chromosome 16, (E) induced interspecific MEL hybrids, and (F) human primary erythroblasts. The $y$-axis represents enrichment over input DNA, normalized to a control sequence in the Gapdh gene (mouse) or 185 (human). The $x$-axis represents the positions of the TaqMan probes used. The coding sequence is represented by the three exons (Promoter/Ex1, Ex2, and Ex3) of the a-globin genes. HS- primer sets refer to upstream DNase-hypersensitive regions. Zeta pr refers to the mouse and human embryonic a-globin promoters (Hba-x and HBZ). Inter, refers to the intergenic region (between mouse Hba-a1 and Hba-a2). 5' and 3' are negative controls flanking the $\alpha$-globin gene. $\beta$-actin and $\beta$-globin denote control sequences at the $\beta$-actin gene and $\beta$-globin promoter respectively. Error bars correspond to \pm 1 standard deviation from at least two independent ChIPs.

6.3-fold and 4.9-fold respectively compared to $\mathrm{Klf3}^{+/+}$cells) (Figure 5B and 5C). Furthermore, stable rescue of $\mathrm{Klf3}^{-/-}$ MEFs with V5-tagged KLF3 resulted in a significant diminution of $\alpha$-globin mRNA expression (Figure 5D).

To explore KLF3's potential mode of regulation at the $\alpha$-globin locus in non-erythroid cells, we analyzed recently generated KLF3 ChIP-Seq data from MEF cells [24]. We found that in these cells, KLF3 was not bound to the adult $\alpha$-globin promoters (Hba-a1 and Hba-a2), but showed significant occupancy at the upstream HS-12 and HS-26 regulatory regions (Figure $5 \mathrm{E}$ ). This contrasted with our observation from a series of erythroid cells (Figure 4), in which KLF3 was primarily found at the $\alpha$-globin promoter. Analysis of the HS-26 region revealed two sites resembling the KLF binding consensus via which KLF3 might be recruited. Indeed, EMSA experiments confirmed that both of these sites are recognized by both KLF3 expressed in COS-7 cells and endogenous KLF3 in MEFs (Figure 5F). Taken together, these findings suggest that in non-erythroid cells, KLF3 binds the HS-12 and HS-26 regulatory regions and may be involved in repressing and thereby maintain physiologically low levels of $\alpha$-globin expression in these cells.

Lastly, we also analyzed the DNA-binding capacity of KLF3 extracted from erythroid (MEL) and non-erythroid (MEF) cells (Figure 6A and B). Equivalent levels of KLF3 from these two cellular sources exhibited comparable DNA-binding activity at sites in both the murine $\alpha$-globin promoter and the $H S-26$ regulatory element. This suggests that the differing in vivo occupancy of KLF3 across the $\alpha$-globin locus in erythroid and non-erythroid cells (compare Figures $4 \mathrm{~B}$ and $4 \mathrm{C}$ with Figure $5 \mathrm{E}$ ) is not due to intrinsic differences in KLF3's ability to bind DNA.

\section{Discussion}

Our data show that KLF3 binds the adult mouse $\alpha$-globin promoter in erythroid tissue in vivo. However, KLF3 does not appear to functionally repress the endogenous promoter in red blood cells. Similarly, we have previously observed KLF3 occupancy at the adult $\beta$-globin (Hbb-b1) promoter in erythroid cells and no associated perturbation 


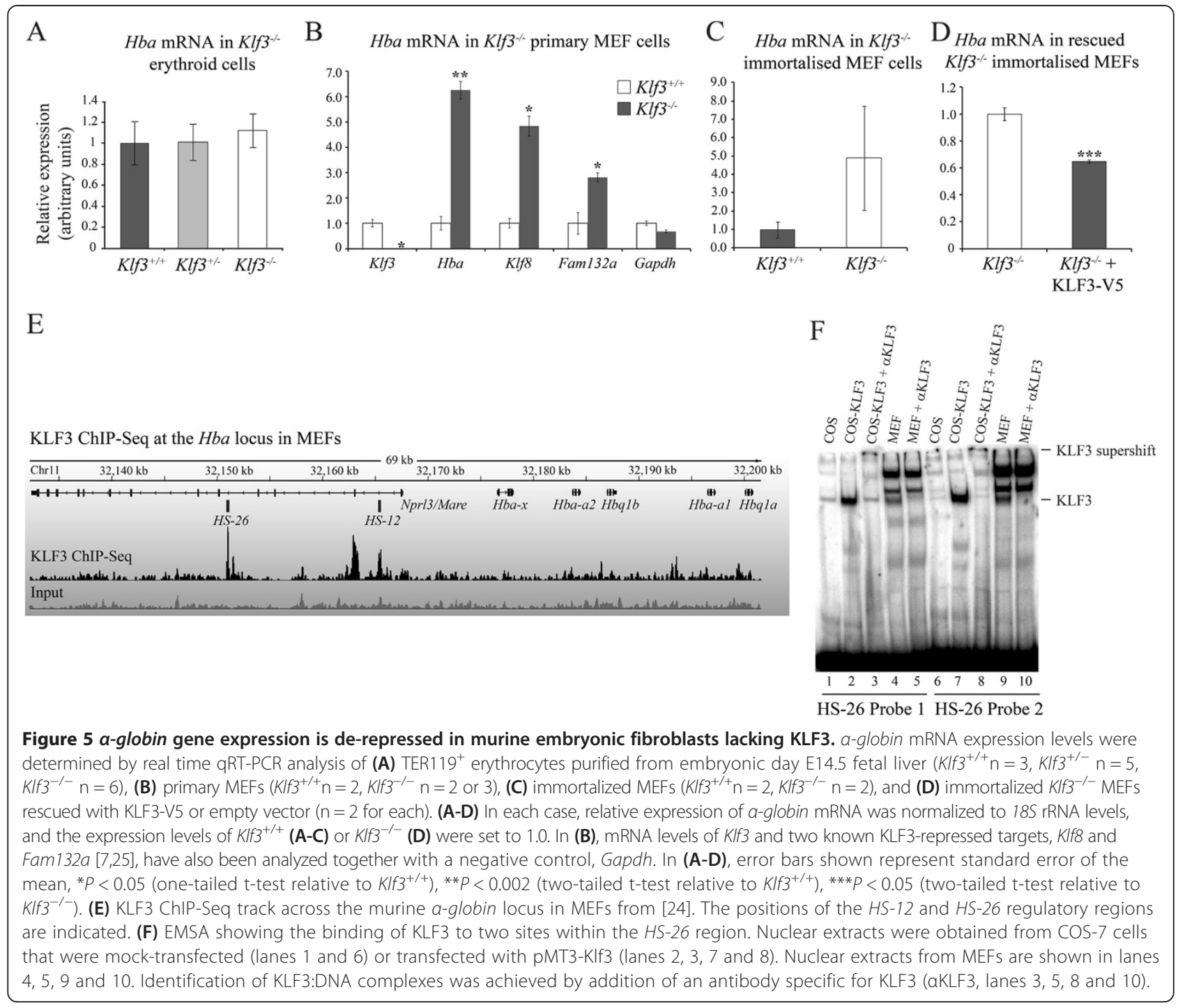

of $H b b-b 1$ transcription upon ablation of KLF3 [6]. It is notable that KLF3 binding is highest at the late stages of erythroid maturation (compare Figure $4 \mathrm{~A}$ with $4 \mathrm{~B}$, and $4 \mathrm{D}$ with 4E) when the adult globin genes are expressed at very high levels and their promoters are presumably highly accessible. This is also when KLF3 levels peak [5] and it is possible that KLF3 gains access to these regions but is not sufficiently potent to limit KLF1 driven activation of the genes. This observation highlights the view that transcription factor binding sites discovered by ChIP may not always have functional relevance in the context in which they are identified, but may instead reflect the dynamic nature of transcription factor binding at permissive loci. Indeed, a number of recent ChIP-Seq experiments, performed in association with transcriptome analysis of gene knockout models have revealed that transcription factor binding is not always associated with changes in gene activity $[34,35]$.
In contrast to the endogenous mouse $\alpha$-globin promoter, we have shown that KLF3 does appear to regulate the expression of a human transgenic promoter in erythroid cells. The transgene is driven by a minimal human $\alpha$-globin promoter and HS-40 and perhaps this subset of elements is more reliant on repression by KLF3 than the entire set of globin regulatory elements. In the case of the endogenous $\alpha$-globin locus, chromatin conformation capture experiments suggest that gene expression is dependent upon chromosomal looping of distal enhancers to the proximal promoter, in a process that is dependent upon many regulatory factors [17]. The removal of such complexity in the transgene most likely offers a far greater opportunity for observing the contribution that single factors make to expression levels. Alternatively, it should be noted that the experiments presented here primarily analyzed KLF3 function in murine cells, and thus it remains possible that KLF3 


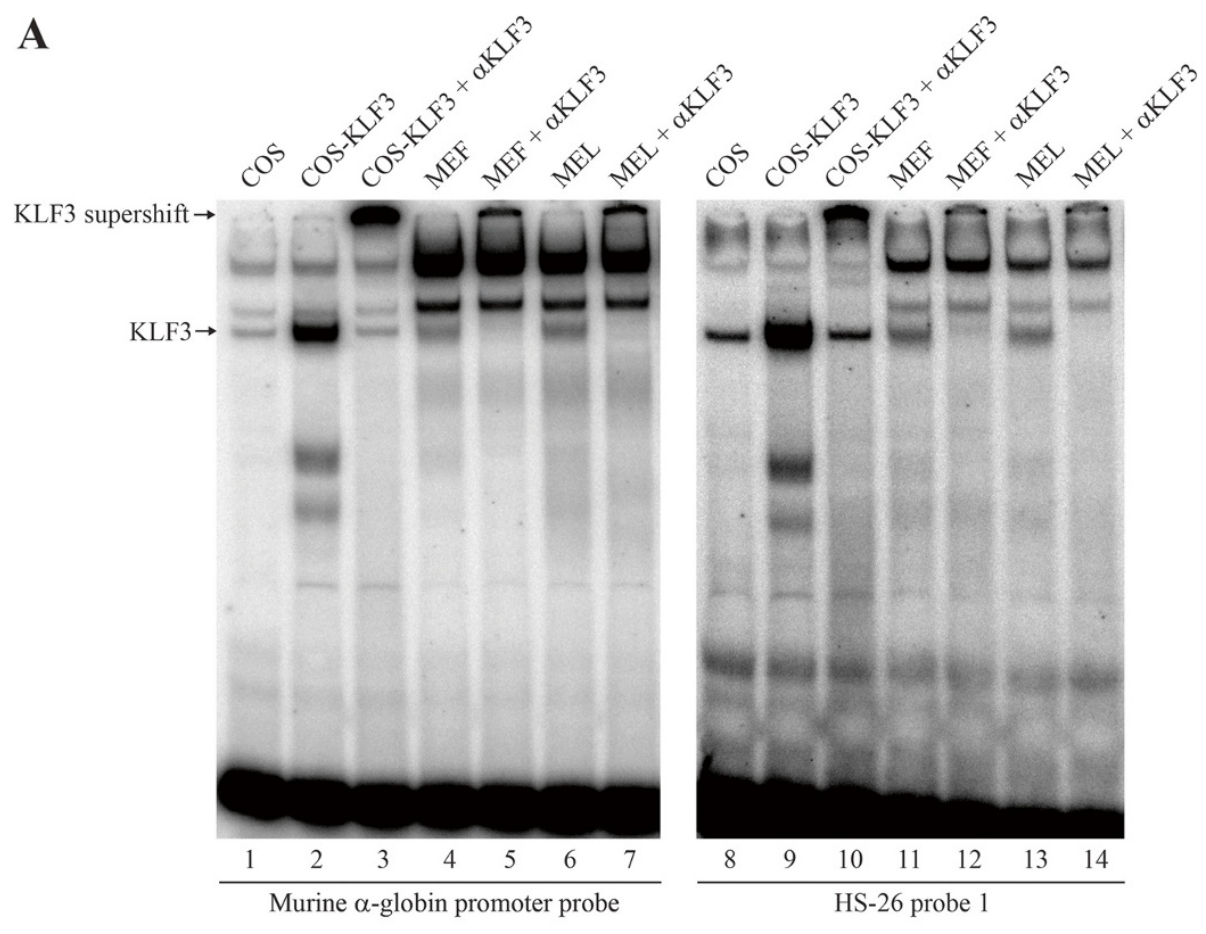

B

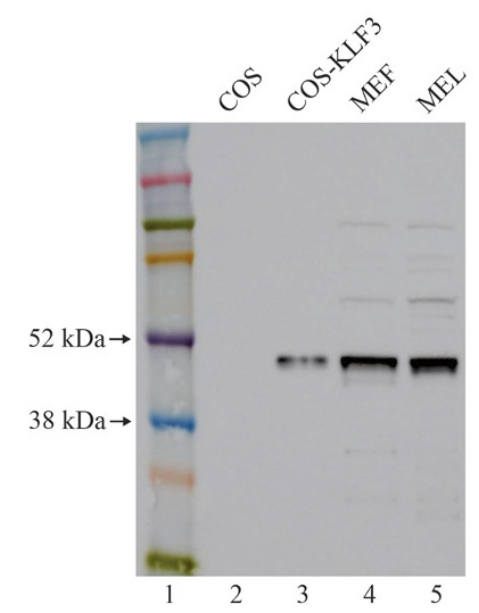

Figure 6 KLF3 from erythroid and non-erythroid cells display similar DNA-binding abilities in vitro. (A) EMSAs were employed to assess the binding of KLF3 to the murine a-globin promoter (lanes 1-7) and a site in the HS-26 element from Figure 5 (lanes 8-14). Nuclear extracts were harvested from non-erythroid MEF (lanes 4, 5, 11 and 12) or erythroid MEL cells (lanes 6, 7, 13 and 14). Nuclear extracts from mock transfected COS-7 cells (lanes 1 and 8) or cells expressing KLF3 (lanes 2, 3, 9 and 10) were included as negative and positive controls respectively. The identity of KLF3 was confirmed by specific antibody supershifts (lanes 3, 5, 7, 10, 12 and 14). (B) Western blot demonstrating the relative amounts of KLF3 in MEF (lane 4) and MEL (lane 5) nuclear extracts used in the EMSAs in (A). As negative and positive controls, COS and COS-KLF3 nuclear extracts have been included (lanes 2 and 3) at 20-fold lower relative amounts than in (A) to facilitate visualization. A size ladder is shown in lane 1.

may play a role in $\alpha$-globin regulation in human erythroid cells. Indeed, the related factor KLF4 has been shown to positively regulate the human $\alpha$-globin promoter in reporter assays and to drive the endogenous $H B A$ gene in $\mathrm{K} 562$ cells [36].

The up-regulation of GFP expression in Line3::Klf3 ${ }^{-/-}$ mice shows that KLF3 can functionally repress the transgenic $\alpha$-globin regulatory sequences in vivo, and may function as an epigenetic modifier of transgene expression.
KLF3 mediates repression of its target genes by binding the co-repressor CtBP [4], which in turn recruits a repressive complex that includes several epigenetic modifiers, such as LSD1, G9A, EUHMT, PC2, HDAC1, and HDAC2 $[37,38]$. These factors facilitate histone methylation, demethylation and deacetylation, and are responsible for the addition of repressive epigenetic marks and gene silencing. It is possible that the absence of KLF3 in Line3::Klf3 ${ }^{-/-}$ erythrocytes prevents $\mathrm{CtBP}$ from being recruited to the 
transgene, and it is this that allows the rewriting of epigenetic marks permissive for transcription, resulting in the up-regulation of GFP expression. Indeed, the Line3 mice have frequently been used in ENU mutagenesis screens for modulators of variegated expression, and these screens have predominantly culminated in the identification of epigenetic modifiers, including HDAC1 [39-43].

Another possible explanation for the lack of de-repression of the endogenous $\alpha$-globin gene in red blood cells is that the locus is already fully open and maximally expressed, so significant further de-repression cannot occur. In contrast, the transgene contains only a limited subset of regulatory sequences, and may therefore be expressed at lower levels allowing its up-regulation in the absence of KLF3. To circumvent this, we examined regulation in murine embryonic fibroblasts, as $\alpha$-globin mRNA expression is limited to low but detectable levels in this cell type. In these nonerythroid cells, we identified a modest but significant increase in $\alpha$-globin gene expression in the absence of KLF3. Moreover, in support of a role for CtBP in the regulation of the $\alpha$-globin locus, we note that another group have observed a similar de-repression (4-fold) of $\alpha$-globin gene expression from microarray analysis of $C t b p^{-/-}$murine embryonic fibroblasts [44].

Both the human and mouse $\alpha$-globin loci lie in an open chromosomal region, surrounded by a number of actively expressed genes and in non-erythroid cells these loci retain the hallmarks of constitutively accessible chromatin [45]. This contrasts significantly with the more isolated $\beta$-globin gene cluster, where in non-erythroid cells a silent heterochromatic state is established and maintained. It therefore appears that the $\alpha$-globin locus employs different silencing mechanisms to prevent expression in nonred blood cells. In the case of the human locus, this is achieved by targeted recruitment of the repressive polycomb complex, PRC2, to CpG islands in the promoter regions [45]. However, these $\mathrm{CpG}$ islands have been significantly eroded in the murine $\alpha$-globin locus (Figure 2) and recruitment of PRC2 has not been detected, most likely due to loss of polycomb recruitment sites [46]. The mechanism of $\alpha$-globin gene silencing in non-erythroid tissue in the mouse therefore remains unclear. Here we suggest that KLF3 participates in this silencing and may do so not through direct interaction with the $\alpha$-globin proximal promoter but via distal regulatory regions such as $H S$-26. In erythroid cells, $H S$-26 is an enhancer element that loops to the $\alpha$-globin promoter and is required for appropriate regulation of expression [17]. In non-erythroid cells, such looping is disrupted and occurs at a much lesser frequency [47]. Whilst these observations allude to the functional importance of the HS-26 element, it should be noted that loss of $H S-26$ only modestly deregulates $\alpha$-globin expression in erythroid cells and has not been reported to perturb non-erythroid silencing [48,49].
Thus it is likely that correct tissue-specific control of the locus is achieved by a complex interplay between multiple cis-acting regulatory regions and positivelyand negatively-acting trans factors such as KLF3 and KLF1.

\section{Conclusions}

Excessive $\alpha$-globin expression can be detrimental to cells and thus it is important that mechanisms exist to limit its expression. Collectively, the findings presented here suggest that the broadly expressed transcriptional repressor KLF3 may have a role in silencing the $\alpha$-globin locus in some but not all contexts, and in particular in non-erythroid tissues. These results complement the previous observation that the KLF3 co-repressor CtBP is also required for the appropriate control of $\alpha$-globin expression in non-erythroid cells [44].

\section{Competing interests}

The authors declare that they have no competing interests.

\section{Authors' contributions}

RCMP, APWF and MC designed the study and wrote the manuscript. DV, $K G R Q, D R H$ and EW coordinated and oversaw experiments, and assisted in manuscript preparation. RCMP performed FACS analysis. APWF, KSM and GEM conducted EMSA experiments. DV, WFL, BW, JB and KSM performed ChIP studies. CMA generated MEF cell lines. APWF and WFL conducted qRT-PCR. All authors have read, contributed to, and approved the final manuscript.

\section{Acknowledgements}

This work is supported by funding from the Australian National Health and Medical Research Council and the Australian Research Council.

\section{Author details}

${ }^{1}$ School of Biotechnology and Biomolecular Sciences, University of New South Wales, Sydney, NSW 2052, Australia. ${ }^{2}$ The Roslin Institute, University of Edinburgh, Easter Bush Campus, Midlothian EH25 9RG, UK. ${ }^{3}$ MRC Molecular Haematology Unit, Weatherall Institute of Molecular Medicine, University of Oxford, John Radcliffe Hospital, Headington, Oxford OX3 9DS, UK. ${ }^{4}$ La Trobe Institute for Molecular Science, La Trobe University, Melbourne, Victoria 3086, Australia.

Received: 30 October 2013 Accepted: 6 May 2014

Published: 16 May 2014

\section{References}

1. McConnell BB, Yang W: Mammalian Kruppel-like factors in health and diseases. Physiol Rev 2010, 90(4):1337-1381.

2. Pearson RC, Funnell AP, Crossley M: The mammalian zinc finger transcription factor Kruppel-like factor 3 (KLF3/BKLF). IUBMB life 2011, 63(2):86-93.

3. Pearson R, Fleetwood J, Eaton S, Crossley M, Bao S: Kruppel-like transcription factors: A functional family. Int J Biochem Cell Biol 2008, 40(10):1996-2001.

4. Turner J, Crossley M: Cloning and characterization of mCtBP2, a co-repressor that associates with basic Kruppel-like factor and other mammalian transcriptional regulators. Embo J 1998, 17(17):5129-5140.

5. Funnell AP, Norton LJ, Mak KS, Burdach J, Artuz CM, Twine NA, Wilkins MR, Power CA, Hung TT, Perdomo J, Koh P, Bell-Anderson KS, Orkin SH, Fraser ST, Perkins AC, Pearson RC, Crossley M: The CACCC-binding protein KLF3/BKLF represses a subset of KLF1/EKLF target genes and is required for proper erythroid maturation in vivo. Mol Cell Biol 2012, 32(16):3281-3292.

6. Funnell AP, Mak KS, Twine NA, Pelka GJ, Norton LJ, Radziewic T, Power M, Wilkins MR, Bell-Anderson KS, Fraser ST, Perkins AC, Tam PP, Pearson RC, Crossley M: Generation of Mice Deficient in both KLF3/BKLF and KLF8 
Reveals a Genetic Interaction and a Role for These Factors in Embryonic Globin Gene Silencing. Mol Cell Biol 2013, 33(15):2976-2987.

7. Bell-Anderson KS, Funnell AP, Williams H, Mat Jusoh H, Scully T, Lim WF, Burdach JG, Mak KS, Knights AJ, Hoy AJ, Nicholas HR, Sainsbury A, Turner N, Pearson RC, Crossley M: Loss of Kruppel-like factor 3 (KLF3/BKLF) leads to upregulation of the insulin-sensitizing factor adipolin (FAM132A/CTRP12/ C1qdc2). Diabetes 2013, 62(8):2728-2737.

8. Sue N, Jack BH, Eaton SA, Pearson RC, Funnell AP, Turner J, Czolij R, Denyer G, Bao S, Molero-Navajas JC, Perkins A, Fujiwara Y, Orkin SH, Bell-Anderson K, Crossley M: Targeted disruption of the basic Kruppel-like factor gene (KIf3) reveals a role in adipogenesis. Mol Cell Biol 2008, 28(12):3967-3978.

9. Himeda CL, Ranish JA, Pearson RC, Crossley M, Hauschka SD: KLF3 regulates muscle-specific gene expression and synergizes with serum response factor on KLF binding sites. Mol Cell Biol 2010, 30(14):3430-3443.

10. Vu TT, Gatto D, Turner V, Funnell AP, Mak KS, Norton LJ, Kaplan W, Cowley MJ, Agenès F, Kirberg J, Brink R, Pearson RC, Crossley M: Impaired B cell development in the absence of Kruppel-like factor 3. J Immunol 2011, 187(10):5032-5042.

11. Turchinovich G, Vu TT, Frommer F, Kranich J, Schmid S, Alles M, Loubert JB, Goulet JP, Zimber-Strobl U, Schneider P, Bachl J, Pearson R, Crossley M, Agenès F, Kirberg J: Programming of marginal zone B-cell fate by basic Kruppel-like factor (BKLF/KLF3). Blood 2011, 117(14):3780-3792

12. Funnell AP, Maloney CA, Thompson LJ, Keys J, Tallack M, Perkins AC, Crossley M: Erythroid Kruppel-like factor directly activates the basic Kruppel-like factor gene in erythroid cells. Mol Cell Biol 2007, 27(7):2777-2790.

13. Siatecka M, Bieker JJ: The multifunctional role of EKLF/KLF1 during erythropoiesis. Blood 2011, 118(8):2044-2054.

14. Tallack MR, Perkins AC: KLF1 directly coordinates almost all aspects of terminal erythroid differentiation. IUBMB life 2010, 62(12):886-890.

15. Nuez B, Michalovich D, Bygrave A, Ploemacher R, Grosveld F: Defective haematopoiesis in fetal liver resulting from inactivation of the EKLF gene. Nature 1995, 375(6529):316-318.

16. Perkins AC, Sharpe AH, Orkin SH: Lethal beta-thalassaemia in mice lacking the erythroid CACCC-transcription factor EKLF. Nature 1995, 375(6529):318-322.

17. Vernimmen D, De Gobbi M, Sloane-Stanley JA, Wood WG, Higgs DR: Long-range chromosomal interactions regulate the timing of the transition between poised and active gene expression. Embo J 2007, 26(8):2041-2051.

18. Shyu YC, Wen SC, Lee TL, Chen X, Hsu CT, Chen H, Chen RL, Hwang JL, Shen CK: Chromatin-binding in vivo of the erythroid kruppel-like factor, EKLF, in the murine globin loci. Cell Res 2006, 16(4):347-355.

19. Tallack MR, Whitington $T$, Yuen WS, Wainwright EN, Keys JR, Gardiner BB, Nourbakhsh E, Cloonan N, Grimmond SM, Bailey TL, Perkins AC: A global role for KLF1 in erythropoiesis revealed by ChIP-seq in primary erythroid cells. Genome Res 2010, 20(8):1052-1063.

20. Vernimmen D, Marques-Kranc F, Sharpe JA, Sloane-Stanley JA, Wood WG, Wallace HA, Smith AJ, Higgs DR: Chromosome looping at the human alpha-globin locus is mediated via the major upstream regulatory element (HS -40). Blood 2009, 114(19):4253-4260.

21. Drissen R, Palstra RJ, Gillemans N, Splinter E, Grosveld F, Philipsen S, de Laat W: The active spatial organization of the beta-globin locus requires the transcription factor EKLF. Genes Dev 2004, 18(20):2485-2490.

22. Preis Jl, Downes M, Oates NA, Rasko JE, Whitelaw E: Sensitive flow cytometric analysis reveals a novel type of parent-of-origin effect in the mouse genome. Curr Biol 2003, 13(11):955-959.

23. Reddel RR, De Silva R, Duncan EL, Rogan EM, Whitaker NJ, Zahra DG, Ke Y, McMenamin MG, Gerwin BI, Harris CC: SV40-induced immortalization and ras-transformation of human bronchial epithelial cells. Int J Cancer 1995, 61(2):199-205

24. Burdach J, Funnell AP, Mak KS, Artuz CM, Wienert B, Lim WF, Tan LY Pearson RC, Crossley M: Regions outside the DNA-binding domain are critical for proper in vivo specificity of an archetypal zinc finger transcription factor. Nucleic Acids Res 2014, 42(1):276-289.

25. Eaton SA, Funnell AP, Sue N, Nicholas H, Pearson RC, Crossley M: A Network of Kruppel-like Factors (Klfs): Klf8 is repressed by Klf3 and activated by Klf1 in vivo. J Biol Chem 2008, 283(40):26937-26947.

26. Hancock D, Funnell A, Jack B, Johnston J: Introducing undergraduate students to real-time PCR. Biochem Mol Biol Educ Bimonthly Publication Int Union Biochem Mol Biol 2010, 38(5):309-316.

27. Crossley M, Whitelaw E, Perkins A, Williams G, Fujiwara Y, Orkin SH: Isolation and characterization of the CDNA encoding BKLF/TEF-2, a major CACCC-box-binding protein in erythroid cells and selected other cells. Mol Cell Biol 1996, 16(4):1695-1705.

28. Perdomo J, Verger A, Turner J, Crossley M: Role for SUMO modification in facilitating transcriptional repression by BKLF. Mol Cell Biol 2005, 25(4):1549-1559.

29. Anguita E, Hughes J, Heyworth C, Blobel GA, Wood WG, Higgs DR: Globin gene activation during haemopoiesis is driven by protein complexes nucleated by GATA-1 and GATA-2. Embo J 2004, 23(14):2841-2852.

30. Robinson JT, Thorvaldsdottir H, Winckler W, Guttman M, Lander ES, Getz G, Mesirov JP: Integrative genomics viewer. Nat Biotechnol 2011, 29(1):24-26.

31. Mak KS, Burdach J, Norton $\sqcup$, Pearson RCM, Crossley M, Funnell APW: Repression of chimeric transcripts emanating from endogenous retrotransposons by a sequence-specific transcription factor. Genome Biol 2014, 15:4.

32. Miller IJ, Bieker JJ: A novel, erythroid cell-specific murine transcription factor that binds to the CACCC element and is related to the Kruppel family of nuclear proteins. Mol Cell Biol 1993, 13(5):2776-2786.

33. Deisseroth A, Hendrick D: Human alpha-globin gene expression following chromosomal dependent gene transfer into mouse erythroleukemia cells. Cell 1978, 15(1):55-63.

34. Biggin MD: Animal transcription networks as highly connected, quantitative continua. Dev Cell 2011, 21(4):611-626.

35. Li XY, MacArthur S, Bourgon R, Nix D, Pollard DA, lyer VN, Hechmer A, Simirenko L, Stapleton M, Luengo Hendriks CL, Chu HC, Ogawa N, Inwood W, Sementchenko V, Beaton A, Weiszmann R, Celniker SE, Knowles DW, Gingeras T, Speed TP, Eisen MB, Biggin MD: Transcription factors bind thousands of active and inactive regions in the Drosophila blastoderm. PLOS Biol 2008, 6(2):e27.

36. Marini MG, Porcu L, Asunis I, Loi MG, Ristaldi MS, Porcu S, Ikuta T, Cao A, Moi P: Regulation of the human HBA genes by KLF4 in erythroid cell lines. Br J Haematol 2010, 149(5):748-758.

37. Shi Y, Sawada J, Sui G, Affar EB, Whetstine JR, Lan F, Ogawa H, Luke MP, Nakatani Y, Shi Y: Coordinated histone modifications mediated by a CtBP co-repressor complex. Nature 2003, 422(6933):735-738.

38. Kagey MH, Melhuish TA, Wotton D: The polycomb protein Pc2 is a SUMO E3. Cell 2003, 113(1):127-137.

39. Daxinger L, Harten SK, Oey H, Epp T, Isbel L, Huang E, Whitelaw N, Apedaile A, Sorolla A, Yong J, Bharti V, Sutton J, Ashe A, Pang Z, Wallace N, Gerhardt DJ, Blewitt ME, Jeddeloh JA, Whitelaw E: An ENU mutagenesis screen identifies novel and known genes involved in epigenetic processes in the mouse. Genome Biol 2013, 14(9):R96.

40. Blewitt ME, Vickaryous NK, Hemley SJ, Ashe A, Bruxner TJ, Preis Jl, Arkell R, Whitelaw E: An N-ethyl-N-nitrosourea screen for genes involved in variegation in the mouse. Proc Natl Acad Sci U S A 2005, 102(21):7629-7634.

41. Chong S, Vickaryous N, Ashe A, Zamudio N, Youngson N, Hemley S, Stopka T, Skoultchi A, Matthews J, Scott HS, de Kretser D, O'Bryan M, Blewitt M, Whitelaw E: Modifiers of epigenetic reprogramming show paternal effects in the mouse. Nat Genet 2007, 39(5):614-622.

42. Ashe A, Morgan DK, Whitelaw NC, Bruxner TJ, Vickaryous NK, Cox LL, Butterfield NC, Wicking C, Blewitt ME, Wilkins SJ, Anderson GJ, Cox TC, Whitelaw E: A genome-wide screen for modifiers of transgene variegation identifies genes with critical roles in development. Genome Biol 2008 9(12):R182.

43. Whitelaw NC, Chong S, Morgan DK, Nestor C, Bruxner TJ, Ashe A, Lambley E, Meehan $R$, Whitelaw E: Reduced levels of two modifiers of epigenetic gene silencing, Dnmt3a and Trim28, cause increased phenotypic noise. Genome Biol 2010, 11(11):R111.

44. Grooteclaes M, Deveraux Q, Hildebrand J, Zhang Q, Goodman RH, Frisch SM: C-terminal-binding protein corepresses epithelial and proapoptotic gene expression programs. Proc Natl Acad Sci U S A 2003, 100(8):4568-4573.

45. Garrick D, De Gobbi M, Samara V, Rugless M, Holland M, Ayyub H, Lower K Sloane-Stanley J, Gray N, Koch C, Dunham I, Higgs DR: The role of the polycomb complex in silencing alpha-globin gene expression in nonerythroid cells. Blood 2008, 112(9):3889-3899.

46. Lynch MD, Smith AJ, De Gobbi M, Flenley M, Hughes JR, Vernimmen D, Ayyub H, Sharpe JA, Sloane-Stanley JA, Sutherland L, Meek S, Burdon T, Gibbons RJ, Garrick D, Higgs DR: An interspecies analysis reveals a key role for unmethylated $\mathrm{CpG}$ dinucleotides in vertebrate Polycomb complex recruitment. Embo J 2012, 31(2):317-329

47. Zhou GL, Xin L, Song W, Di LJ, Liu G, Wu XS, Liu DP, Liang CC: Active chromatin hub of the mouse alpha-globin locus forms in a transcription factory of clustered housekeeping genes. Mol Cell Biol 2006, 26(13):5096-5105. 
48. Bouhassira EE, Kielman MF, Gilman J, Fabry MF, Suzuka S, Leone O, Gikas E, Bernini LF, Nagel RL: Properties of the mouse alpha-globin HS-26: relationship to HS-40, the major enhancer of human alpha-globin gene expression. Am J Hematol 1997, 54(1):30-39.

49. Anguita E, Sharpe JA, Sloane-Stanley JA, Tufarelli C, Higgs DR, Wood WG: Deletion of the mouse alpha-globin regulatory element ( $\mathrm{HS}-26)$ has an unexpectedly mild phenotype. Blood 2002, 100(10):3450-3456.

doi:10.1186/1471-2199-15-8

Cite this article as: Funnell et al:: Differential regulation of the $a$-globin locus by Krüppel-like factor 3 in erythroid and non-erythroid cells. BMC Molecular Biology 2014 15:8.

\section{Submit your next manuscript to BioMed Central and take full advantage of:}

- Convenient online submission

- Thorough peer review

- No space constraints or color figure charges

- Immediate publication on acceptance

- Inclusion in PubMed, CAS, Scopus and Google Scholar

- Research which is freely available for redistribution 